\title{
CRIMEAN-CONGO HAEMORRHAGIC FEVER WITHOUT BLEEDING
}

\section{Radka KOMITOVA ${ }^{1,2} \bowtie$, Ani KEVORKYAN ${ }^{3}$, Oliana BOYKINOVA ${ }^{1,2}$, Iva CHRISTOVA ${ }^{4}$, Vanya RANGELOVA ${ }^{3}$}

${ }^{1}$ Department of Infectious Diseases, Parasitology and Tropical Medicine, Faculty of Medicine, Medical University-Plovdiv, Bulgaria

${ }^{2}$ Department of Infectious Diseases "St George“ University Hospital, Plovdiv, Bulgaria

${ }^{3}$ Department of Epidemiology and Disaster Medicine, Faculty of Public Health, Medical University-Plovdiv, Bulgaria

${ }^{4}$ National Reference Laboratory of Vector-borne Infections, Listeria and Leptospira, National Center for Infectious and Parasitic Diseases, Sofia, Bulgaria

Received 17 Sept 2020, Accepted 29 Oct 2020

https://doi.org/10.31688/ABMU.2020.55.4.17

\section{Abstract}

Introduction. Crimean-Congo hemorrhagic fever (CCHF) is the most widespread tick-borne infection, but an underestimated cause of febrile illness, especially in the absence of bleeding.

The objective of the study was to analyze atypical CCHF presentation, which poses difficulties in diagnosing the infection.

Material and methods. We conducted a retrospective study on febrile patients without bleeding who resided or visited endemic areas for CCHF between June and August, 2018, in Bulgaria. Polymerase chain reaction (PCR) and enzyme-linked immune-sorbent assay (ELISA) were performed to test for CCHF virus. In case of a suggestive medical history, the patients were deemed either confirmed (based on serology and/or PCR) or probable (based on epidemiology).

Results. Five out of 6 serologically confirmed patients with CCHF without bleeding were studied.

\section{RésumÉ}

Fièvre hémorragique de Crimée-Congo sans saignement

Introduction. La fièvre hémorragique de CriméeCongo (FHCC) est l'infection transmise par les tiques, la plus répandue mais sous-estimée cause de la maladie fébrile, en particulier en l'absence de saignement.

L'objectif de l'étude. Nous avons essayé d'analyser la présentation atypique de la CCHF qui représente une difficulté à diagnostiquer l'infection.

Matériel et méthodes. Nous avons mené une étude rétrospective chez des patients fébriles sans hémorragie ayant siégé ou visité des zones endémiques de la FHCC entre juin et août 2018, en Bulgarie. Une réaction en chaîne par polymérase (PCR) et un test immuno-enzymatique lié à une enzyme (ELISA) ont été réalisés pour tester le virus CCHF. En cas d'antécédents médicaux adaptés, les cas ont été jugés soit confirmés (à base de 
Three of the patients, referred from another hospital, were correctly diagnosed at admission, yet the other two patients were misdiagnosed initially. Laboratory investigations at admission were notable for thrombocytopenia and leucopenia (in four patients) and normal coagulation parameters. All patients received intensive care support, including intravenous fluids, platelet concentrate and fresh frozen plasma. Three patients were given steroids. All patients recovered uneventfully.

Conclusions. This case series study shows that CCHF without bleeding is an important and poorly recognized cause of illness in endemic areas, even in infectious diseases clinics. A lower threshold to test for CCHF would be warranted in patients with febrile illness in endemic areas.

Keywords: Crimean-Congo hemorrhagic fever, haemorrhage, flu-like illness.

\section{Abbreviations :}

CCHF - Crimean-Congo hemorrhagic fever ELISA- enzyme-linked immuno-sorbent assay PCR - polymerase chain reaction

\section{INTRODUCTION}

Crimean-Congo hemorrhagic fever (CCHF) has been recognized as the most widespread tick-borne infection affecting humans ${ }^{1}$. The disease is caused by the CCHF virus of the family Bunyaviridae. Hyalomma spp. ticks are the reservoirs and the main competent vectors ${ }^{2}$. The disease is endemic in Africa, Asia, Middle East, and the Balkans. Bulgaria, situated on the Balkan Peninsula, is among the countries endemic for $\mathrm{CCFF}^{3}$. CCHF is associated with high fatality rate, nosocomial potential and is considered a major public health threat ${ }^{4}$. Clinical spectrum may range from asymptomatic infection to life-threatening hemorrhagic disease, especially when treatment is delayed. Therefore, most studies to date have included only symptomatic cases. Not uncommonly CCHF is only considered in the late stage of disease before the bleedings appear. This delay may inflict the adequate patient management and increase the risk for nosocomial transmission ${ }^{5}$. On the other hand, recognition of CCHF can be difficult, as many patients develop only mild nonspecific febrile illness, without hemorrhagic syndrome. As a result, the disease remains underreported, particularly in many rural endemic parts, due to low index of suspicion. The true incidence of CCHF infection, full spectrum of diseases severity and its epidemiological features are not completely la sérologie et/ ou de la PCR) soit probables (à base de l'épidémiologie).

Résultats. Cinq des 6 patients atteints d'ESCC confirmés par la sérologie sans saignement ont été étudiés. Trois de ces patients, référés d'un autre hôpital, ont été correctement diagnostiqués à l'admission, mais les deux autres patients ont été mal diagnostiqués au départ. Les examens de laboratoire à l'admission étaient notables pour la thrombopénie et la leucopénie (chez quatre patients) et les paramètres de coagulation normaux. Tous les patients ont reçu un appui intensif, y compris des liquides intraveineux, des concentrés de plaquettes et du plasma frais congelé. Trois ont reçu des stéroïdes. Tous les patients se sont rétablis sans incident.

Conclusions. Cette étude de série de cas montre que la FHCC sans saignement est une cause importante et mal reconnue de maladie dans les zones endémiques, même en clinique infectieuse. Un seuil plus bas pour tester la CCHF serait justifié chez les patients atteints de maladie fébrile dans les zones endémiques.

Mots-clés: fièvre hémorragique de Crimée-Congo, hémorragie, syndrome grippal.

known ${ }^{6}$. Most of the recent Bulgarian studies are based mainly on molecular epidemiology $y^{7,8,9}$.

The objective of this Study was to analyze the atypical CCHF presentation, which is a diagnostic problem.

\section{Materials AND MEthods}

\section{Patients}

This retrospective study was conducted in "St. George" University Hospital, Plovdiv, Bulgaria. Six patients with confirmed CCHF, admitted to the Department of Infectious Diseases of this hospital, were evaluated during June - August, 2018. "St. George" University Hospital is a tertiary care hospital and is equipped for care of patients with suspicion of hemorrhagic fevers. Five out of these six patients without bleeding were enrolled in the study, three males and two females, between 23 and 79 years of age. To the purpose of this study, cases without hemorrhagic manifestations were accepted as atypical.

\section{Laboratory investigations}

Medical records of the patients were evaluated retrospectively. Patients' blood samples were tested for levels of leucocytes, thrombocytes, erythrocytes, hemoglobin, aspartate aminotransferase (ASAT), alanine aminotransferase (ALAT), prothrombin time (PT) 
and activated partial thromboplastin time (aPTT). Blood samples were sent to the National Reference Laboratory of Vector-Borne Infections, Listeria and Leptospira, National Center of Infectious and Parasitic Diseases (NCIPD), Sofia, Bulgaria, which is the only institution licensed to perform the tests for CCHF. Serum samples were tested for anti-CCHFV IgM and IgG antibodies using commercially available ELISA kits according to the manufacturer's instructions (Vector-Best, Novosibirsk, Russia). CCHF virus RNA was detected by real time RT-PCR ${ }^{10}$.

There are two categories of CCHF as specified in the definition of CCHF by Ordinance 21/18.07.2005 on the procedure for registration, notification and reporting of communicable diseases in Bulgaria: probable and confirmed cases. The probable case is defined as an individual with abrupt onset of temperature, chills, myalgia, vomiting, nausea, headache, back pain, hemorrhagic signs, together with a positive epidemiologic history (animal contact, tick bite, direct contact with tissues of infected animals or blood/secretion of confirmed case). The confirmed case is defined as a probable case with positive microbiology tests ${ }^{11}$.

Written informed consents were obtained from all participants.

\section{Results}

\section{Patients}

Five patients were included in the study. Three out of five were referred from the district hospital of
Kardzhali city with presumptive diagnosis of CCHF (Figure 1). Kardzhali district is endemic for CCHF in Bulgaria. The other two patients (a 78-yo male and a 38-yo female) were admitted directly to our department. The former was diagnosed with probable Rickettsiosis because of temperature and myalgia after a tick bite. Due to lack of effect of doxycycline treatment and worsening thrombocytopenia, his diagnosis was reevaluated and CCHF was suspected. The latter was hospitalized because of severe flu-like symptoms but repeat thrombocytopenia on the following day was the reason to doubt the initial diagnosis of influenza, and also to suspect CCHF. On further questioning, it was revealed that they both went on a summer vacation in mountainous areas in Pazardzhik and Plovdiv regions, respectively, areas that were previously endemic for the infection. All cases experienced initial severe flu-like complaints: fever, headache, myalgia, fatigue, vomiting and short-lived diarrhea. One patient developed maculopapular rash after the admission. All participants had a history of a tick bite and/or a tick exposure.

\section{Laboratory investigations}

Laboratory investigations at admission were notable for thrombocytopenia and leucopenia (in four patients), mild elevation of aminotransferases and normal coagulation parameters (Table 1). Serological tests confirmed CCHF in all cases but blood samples for PCR turned back negative for viral CCHF RNA.

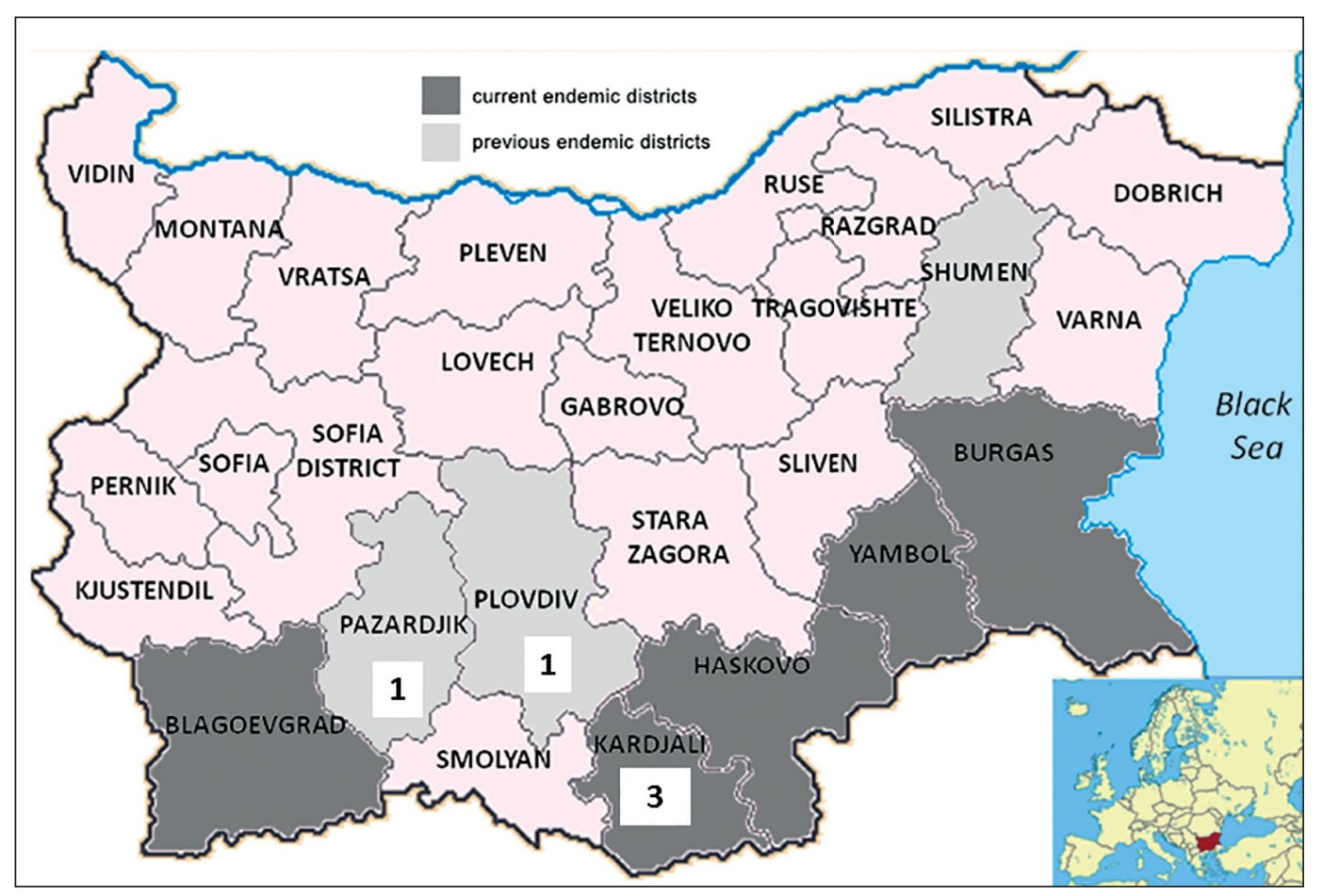

Figure 1. Regions in Bulgaria endemic for $\mathrm{CCHF}$ - previous and current. 
Table 1. The general epidemiological and laboratory data of five patients.

\begin{tabular}{|c|c|c|c|c|c|c|c|c|c|}
\hline Sex & $\begin{array}{l}\text { Age } \\
(\mathrm{y})\end{array}$ & $\begin{array}{l}\text { Residence } \\
\text { (region) }\end{array}$ & $\begin{array}{l}\text { Epidemi- } \\
\text { ology }\end{array}$ & $\begin{array}{c}\text { PLT } \\
\left(10^{9} / \mathrm{L}\right) \\
(\text { initial } \\
\text { count })\end{array}$ & $\begin{array}{l}\text { WBC } \\
\left(10^{9} / \mathrm{L}\right) \\
\text { (initial } \\
\text { count) }\end{array}$ & $\begin{array}{l}\text { Prothrom- } \\
\text { bin time } \\
\text { (PT) } \\
(\%)\end{array}$ & $\begin{array}{l}\text { Activated } \\
\text { partial throm- } \\
\text { boplastin time } \\
(\mathrm{aPTT}) \\
(\mathrm{sec} .)\end{array}$ & $\begin{array}{c}\text { ALAT/ } \\
\text { AST } \\
(\mathrm{U} / 1)\end{array}$ & $\begin{array}{c}\text { Serology } \\
\text { (ELISA) } \\
\text { First/sec- } \\
\text { ond blood } \\
\text { sample }\end{array}$ \\
\hline Female & 55 & Kardzhali & Tick bite & 14 & 1.1 & $\mathrm{~N}$ & $\mathrm{~N}$ & $156 / 68$ & $\mathrm{M}^{+} / \mathrm{M}^{+}, \mathrm{G}^{+}$ \\
\hline Male & 50 & Kardzhali & $\begin{array}{c}\text { Tick } \\
\text { exposure }\end{array}$ & 52 & 2.4 & $\mathrm{~N}$ & $\mathrm{~N}$ & $159 / 197$ & $\mathrm{M}^{+} / \mathrm{M}^{+}, \mathrm{G}^{+}$ \\
\hline Male & 23 & Kardzhali & Tick bite & 71 & 2.0 & $\mathrm{~N}$ & $\mathrm{~N}$ & $79 / 34$ & $\mathrm{M}+/ \mathrm{M}^{+}, \mathrm{G}^{+}$ \\
\hline Male & 78 & Pazardzhik & Tick bite & 14 & 0.7 & $\mathrm{~N}$ & $\mathrm{~N}$ & $297 / 53$ & $\mathrm{M}+/ \mathrm{M}^{+}, \mathrm{G}^{+}$ \\
\hline Female & 38 & Plovdiv & $\begin{array}{c}\text { Tick } \\
\text { exposure }\end{array}$ & 32 & 5,7 & $\mathrm{~N}$ & $\mathrm{~N}$ & 160 & $\mathrm{M}+/ \mathrm{M}^{+}, \mathrm{G}^{+}$ \\
\hline
\end{tabular}

Legend: N - within reference range; white blood cells (WBC) - reference range 3.5-10.5.10\%/L; platelets (PLT) - reference range $140-400 \times 10^{9} / \mathrm{L}$; aPTT - reference range $24-35 \mathrm{sec}$; PT - reference range $70-120 \%$; aspartate aminotransferase (ASAT) - reference range 1-50 IU/L; alanine aminotransferase (ALAT) - reference range 1-50 IU/L.

Table 1 summarizes the general epidemiological and laboratory data of the five patients. All patients received intensive care support, including intravenous fluids, platelet concentrate and fresh frozen plasma. Three were given steroids. All patients recovered uneventfully.

\section{Discussion}

We have presented five cases of CCHF with atypical presentation, i.e. without hemorrhages. Along with the only typical CCHF patient, these patients constituted all the notified CCHF cases in Bulgaria for 2018. The three referred patients were correctly diagnosed at admission, yet the other two patients were misdiagnosed initially. It was only when thrombocytopenia was revealed that CCHF was suspected in these two patients. At first, their tick exposure in previously CCHF endemic areas was missed, which highlighted the significance of a thorough epidemiological history. The important message from the study was that even in a specialized infectious clinic, where clinicians are familiar with CCHF, this diagnosis was nearly missed. In a non-specialized clinical setting, the proportion of missed diagnosis of CCHF would probably be higher. Although no deaths occurred in this case series, all patients were hospitalized, which emphasizes the importance of timely recognition and treatment of the disease.

The first CCHF case in the country was diagnosed in $1952^{12}$ and as of 2018 more than 1600 cases were notified. Human infections were seen mainly in the eastern (Shumen, Burgas) and the southern part of Bulgaria (Plovdiv, Pazardzhik, Haskovo, Kurdzhali $)^{13}$. Thereafter, the incidence markedly decreased (Figure 1). There have been only isolated cases in the last 10 years ${ }^{8}$. However, the disease spreads into new remote area (Blagoevgrad district) ${ }^{14}$. Recently, almost all CCHF cases were reported in five districts, close to the borders with Turkey and Greece: Burgas, Haskovo, Kardzhali, Yambol, and Blagoevgrad. All detected CCHF virus strains in Bulgaria clustered into Europe lineage 1 .

A few recent studies supported the spread of CCHF virus in Bulgaria: human CCHF virus seroprevalence of $3.2 \%$ in 2011-2012 ${ }^{8}$ and high seroprevalence in ruminants (18.4\%), the highest in Kardzhali $(86.7 \%)^{15}$. The last crucial evidence was provided by detection of the two basic lineages of CCHF virus in the ticks in Bulgaria - the pathogenic Europe lineage 1 and the Europe lineage $2^{12}$. The latter contains AP92 and AP92-like strains and has been reported to have low or no pathogenicity, causing only subclinical or mild infections in humans ${ }^{16}$. Europe lineage 2 was detected in Rhipicephalus sanguineus ticks, a potential vector of CCHF virus, from the region of Kardzhali, for the first time in Bulgaria in 2016. Moreover, the infection rate of the ticks with Europe lineage 2 in this region was higher than that of Europe lineage 1 $(40.4 \% \text { versus } 8.6 \%)^{12}$. Kardzhali was the city where exactly three of the patients resided (Figure 1). The presence of fever and other flu-like symptoms in those living in endemic regions, even without bleeding, were highly suggestive of $\mathrm{CCHF}^{17}$.

Another category of atypical cases is represented by those who present only with nonspecific symptoms within the course of the disease. In Turkey, where the highest number of CCHF cases in the world has been reported, $90 \%$ of CCHF infections are subclinical. This might obscure the true incidence of infection and the full clinical spectrum ${ }^{6}$. In the same country, during 2002-2006, only 23\% of the reported patients had hemorrhages ${ }^{17}$. It is still not completely clear why CCHF infection develops into severe or even fatal 
disease in some cases, but mild or asymptomatic in another ${ }^{18}$

In this study, we reported case series with $\mathrm{CCHF}$ without hemorrhage for the first time in Bulgaria. Similarly, we found no explanation for the lack of bleeding, despite the low level of thrombocytes. Notably, three of the patients were residents of Kardzhali, the same place where exactly apathogenic AP92-like strain was isolated from ticks. The high ticks infection rate with $\mathrm{CCHF}$ virus and the high human and ruminant seroprevalence, despite a few detected CCHF cases in Kardzhali district, have suggested the widespread circulation of the virus. Of particular interest is the high infection rate of Rhipicephalus sanguineus tick with apathogenic AP92-like strain, even higher than that with Europe lineage 1. This might probably explain the existence of undiagnosed mild or asymptomatic $\mathrm{CCHF}$ infections in the region. Further research is needed to elucidate the association of Europe lineage 2 with human diseases.

The results presented should be interpreted with caution, because of the small number of patients and short duration of the study period.

\section{Conclusions}

Larger prospective studies on complete clinical manifestation of CCHF are warranted. This information would help the precise notification and better surveillance of the disease. Based on the results of our case series, CCHF should be included in the differential diagnosis of febrile illness in endemic regions. Lower threshold to test for CCHF would be justified.

\section{Author Contributions}

Conceptualization: RK. and AK.; methodology: RK and $A K$; software: $A K$ and VR; investigation: RK, $O B$, IC, VR; formal analysis: RK and AK; writing - original draft preparation: $R K$; writing - review and editing: $R K$ and $A K$; supervision: $\mathrm{OB}$ and IC. All the authors have read and agreed with the final version of the article.

\section{Compliance with Ethics Requirements:}

„The authors declare no conflict of interest regarding this article"

„The authors declare that all the procedures and experiments of this study respect the ethical standards in the Helsinki Declaration of 1975, as revised in 2008(5), as well as the national law"

$$
\text { "No funding for this study" }
$$

\section{Acknowledgment}

The authors are grateful to Dr. Marinova, district Hospital in Kardzhali, for referring some of the patients.

\section{References}

1. Al-Abri SS, Abaidani IA, Fazlalipour M, et al. Current status of Crimean-Congo hemorrhagic fever in WHO Eastern Mediterranean Region. Int J Infect Dis. 2017;58:82-89.

2. Papa A, Tsergouli K, Tsioka K, Mirazimi A. Crimean-Congo hemorrhagic fever tick-host-virus interactions. Front Cell Infect Microbiol. 2017;7: 213.

3. Mertens M, Schmidt K, Ozkul A, Groschup MH. The impact of Crimean-Congo hemorrhagic fever virus on public health. Antiviral Res. 2013;98:248-60.

4. CCH Fever Final Report. Project title: Crimean Congo hemorrhagic fever: modern approaches to diagnostics, surveillance prevention, therapy and preparedness. http:// www.cchfvaccine.eu/images/finall-final-report-cchfever.pdf (accessed on 25 Aug 2020)

5. Guven G, Talan L, Altintas ND, Memikoglu KO, Yoruk F, Azap A. An unexpected fatal CCHF case and management of exposed health care workers. Int J Infect Dis. 2017;55:118-121.

6. Bodur H, Akinci E, Ascioglu S, Öngürü P, Uyar Y. Subclinical infections with Crimean-Congo hemorrhagic fever virus, Turkey. Emerg Infect Dis. 2012;18(4):640-2.

7. Papa A, Pappa S. Panaotova E, Papadopoulou E, Christova I. Molecular epidemiology of CCHF in Bulgaria - an update. J Med Virol. 2016;88:769-773.

8. Christova I, Gladnishka T, Taseva E, Kalvatchev N, Tsergouli K, Papa A. Seroprevalence of Crimean-Congo hemorrhagic fever virus, Bulgaria. Emerg Infect Dis. 2013;19(1):177-179.

9. Gergova I, Kamarinchev B. Seroprevalence of Crimean-Congo hemorrhagic fever in south-eastern Bulgaria. Jpn J Infect Dis. 2014;67(5):397-8.

10. Schwarz TF, Nsanze H, Longson M, et al. Polymerase chain reaction for diagnosis and identification of distinct variants of Crimean-Congo hemorrhagic fever virus in the United Arab Emirates. Am J Trop Med Hyg. 1996;55(2):190-196.

11. Ministry of Health in Bulgaria. Ordinance 21/18.072005 on the procedure for registration, notification and reporting of communicable disease State Gazette 2005:62. http://www. lex.bg/en/laws/ldoc/2135508238 [In Bulgarian]

12. Panayotova E, Anna Papa, Iva Trifonova, Iva Christova. Crimean-Congo hemorrhagic fever virus lineages Europe 1 and Europe 2 in Bulgarian ticks. Ticks and Tick-borne Diseases. 2016;7:1024-1028.

13. Papa A, Christova I, Papadimitriou E, Antoniadis A. Crimean-Congo haemorrhagic fever in Bulgaria. Emerg Infect Dis. 2004;10(8):1465-1467.

14. Christova I, Di Caro A, Papa A, et al. Crimean-Congo hemorrhagic fever, Southwestern Bulgaria. Emerg Infect Dis. 2009;15(6): 983-985.

15. Christova I, Panayotova E, Groschup M, Trifonova I, Tchakarova S, Sas M. High seroprevalence for CrimeanCongo haemorrhagic fever virus in ruminants in the absence of reported human cases in many regions of Bulgaria. Experimental and Applied Acarology. 2018;75: 227-234.

16. Midilli K, Gargilı A, Ergonul O, et al. The first clinical case due to AP92 like strain of Crimean Congo Hemorrhagic Fever virus and a field survey. BMC Infect Dis. 2009; 9:90.

17. Ylmaz GR, Buzgan T, Irmak H, et al. The epidemiology of Crimean-Congo hemorrhagic fever in Turkey, 2002-2007. Int J Infect Dis. 2009; 13:380-6.

18. Cevik MA, Erbay A, Bodur H, et al. Clinical and laboratory features of Crimean-Congo hemorrhagic fever: predictors of fatality. Int J Infect Dis. 2009; 12(4):374-9. 